\title{
Opening previously impossible avenues for phase transformation in innovative steels by atom probe tomography Special Issue: APMS, Bhadeshia
}

\author{
F.G. Caballero ${ }^{1}$, M.K. Miller ${ }^{2}$ and C. Garcia-Mateo ${ }^{1}$ \\ ${ }^{1}$ National Center for Metallurgical Research (CENIM-CSIC); \\ Avda Gregorio del Amo, 8; Madrid, E-28040, Spain \\ ${ }^{2}$ Oak Ridge National Laboratory (ORNL), PO Box 2008; Oak Ridge, TN 37831-6139
}

\begin{abstract}
After decades of debate on the mechanism for the formation of bainite, it is accepted that bainite grows via a displacive mechanism i.e., as plate-shaped transformation products exhibiting an invariant plane strain surface relief effect. But there is still much discussion on the diffusion or diffusionless nature of bainite. The purpose of this atom probe tomography study was to track the atom distributions during the bainite reaction in steels with different carbon and silicon contents. The steels were transformed over a wide range of temperatures $\left(200-525^{\circ} \mathrm{C}\right)$ to elucidate the role of reaction rate and diffusion in the formation of bainite with and without cementite precipitation.
\end{abstract}

Keywords: Phase transformations; Bainite; Steels; Atom probe tomography (APT)

\section{Introduction}

Today, it is accepted that bainite grows via a displacive mechanism, ${ }^{1}$ i.e., as lath-shaped transformation products exhibiting an invariant plane strain surface relief effect. However, two different explanations about the growth nature of bainitic ferrite in steels are still discussed: the diffusionless hypothesis, which states that bainitic ferrite grows without any diffusion of carbon, and carbon supersaturation is subsequently relieved by partitioning to austenite, and/or through carbide precipitation; and the diffusional hypothesis, which states that bainitic ferrite growth is controlled by carbon diffusion, and not distinctly different in character from Widmanstätten ferrite, with carbide precipitation at the austenite/ferrite boundaries.

The criterion for distinguishing between the two bainite transformation theories is whether the newly-formed bainitic ferrite has the para-equilibrium (PE) carbon content or if it is super-saturated in carbon. But it is challenge to measure experimentally the carbon concentration of newly formed bainitic ferrite because the time taken for any carbon to diffuse into austenite can be extremely short.

Traditionally, the diffusionless nature of bainitic ferrite of bainitic ferrite growth has been confirmed indirectly in Si-containing steels by determining the carbon content in the retained austenite at the end of the bainite reaction using X-ray diffraction (XRD) analysis and early atom probe analysis. ${ }^{2,3}$ Carbon concentrations of the residual austenite confirming the $T_{o}^{\prime}$ value ${ }^{5}$, where austenite and ferrite of the same chemical composition have the same free energy, indicate that bainite initially forms having a full supersaturation of carbon. The partitioning of carbon into the residual austenite occurs immediately after formation.

The purpose of this atom probe tomography (APT) study was to track the atom distributions during the bainite reaction to elucidate the role of carbon diffusion in the 
formation of bainite. The results show atomic experimental evidence on the $T_{o}^{\prime}$ limit, the carbon supersaturation of bainitic ferrite and secondary processes, such as plastic accommodation and carbide precipitation, which are not essential to the mechanism of formation of bainitic ferrite, except where any precipitation of carbon trapped at dislocations influences the reaction rate by removing carbon from the supersaturated ferrite.

\section{Approaching $T_{o}^{\prime}$ curve during bainite formation}

High carbon high silicon bainitic steels are known to exhibit extremely sluggish transformation to bainite at low temperatures, ${ }^{6}$ which can be advantageous for monitoring carbon distribution during bainitic ferrite growth. The evolution of the carbon content in bainitic ferrite and austenite, as determined from XRD analysis and APT, during transformation at $200{ }^{\circ} \mathrm{C}$ in $\mathrm{Fe}-4.3 \mathrm{C}-2.8 \mathrm{Si}-1.8 \mathrm{Mn}-1.3 \mathrm{Cr}$ (at.-\%) steel is shown in Fig. 1. The XRD data in Fig. 1a clearly indicate that, as the formation of bainitic ferrite progresses, the austenite is gradually enriched in carbon from the overall carbon content to that given by the $T_{o}^{\prime}$ value and well before the paraequilibrium phase boundary value $\left(A e_{3}^{\prime}\right)$.XRD results in Fig. 1a are an indirect manifestation of the diffusionless nature of bainite transformation so that the original bainitic ferrite retains much of the carbon content of the parent austenite.

The APT values are estimated from proximity histograms across the interface between austenite and ferrite regions with a random solid solution. An example of 3D carbon atom map showing austenite and ferrite regions is illustrated in Fig. 2.

The trend of the APT values as function of time in Fig. 1a may not be so obvious. This is a consequence of tvariations in the carbon distributions in different regions of austenite. $^{7}$ The austenite films entrapped between neighbouring sub-units of bainitic ferrite have a higher carbon content than the blocks of residual austenite located between the sheaves of bainite. Moreover, nano-sized austenite films can accumulate higher amounts of carbon during bainite formation. ${ }^{8}$ Thus, Fig. 3 indicates the thickness in $\mathrm{nm}$ of the APT-analyzed austenite regions. Nano-scale austenite films with thicknesses in the range of 5-20 nm show APT values ranging from 9 to 14 at. $\%$, higher than the corresponding XRD and $T_{o}^{\prime}\left(7.0\right.$ at. \%) values and less than the $A e_{3}^{\prime}$ value (20.7 at. \%). Conversely, sub-micron austenite regions exhibit APT estimated carbon contents ranging from 4.77 to 6 at. \%, which is lower than the corresponding XRD and $T_{o}^{\prime}(7.0$ at. $\%)$ values.

\section{Carbon supersaturation of bainitic ferrite in bainite}

The evolution of the carbon content in bainitic ferrite as bainite transformation progresses at $200^{\circ} \mathrm{C}$ in the same high carbon high silicon steel determined by XRD analysis and APT is shown in Fig. 1b. The APT estimates are from selected volumes of ferrite that did not contain any carbon-enriched regions, such as dislocations and boundaries, whereas the higher XRD estimates are average estimates of larger volumes of bainitic ferrite that include such carbon-enriched regions. APT values prove the presence of a high level of carbon in bainitic ferrite, which was well above that expected from paraequilibrium with austenite (PE value of 0.12 at.- $\%$ ), and provide clear 
evidence of carbon supersaturation in bainitic ferrite at the early stage of transformation confirming that the bainite transformation is essentially diffusionless in nature.

However, the lower reaction rate of bainite in comparison to martensite has been traditionally used to support the idea of a diffusional growth mechanism, as it seemed natural to believe that trapping of carbon in the growing ferrite requires faster kinetics than those observed experimentally. In this sense, the carbon content of the bainitic ferrite was analysed by APT in Fe-XC-YSi-1.5Mn- $0.5 \mathrm{Cr}$ at.-\% steels with different carbon contents and silicon contents $(1.3 \mathrm{C}-0.5 \mathrm{Si}, 1.3 \mathrm{C}-2.8 \mathrm{Si}$, and $4.3 \mathrm{C}-2.8 \mathrm{Si}$ in at.- $\%)$ that transforms over a wide range of temperatures $\left(200-525^{\circ} \mathrm{C}\right)$ to elucidate the role of reaction rate and diffusion in the formation of bainite with and without cementite precipitation.

Examples of transmission electron microscopy (TEM) images for the different morphologies of bainite identified in the studied steels are shown elsewhere. ${ }^{9}$ The difference in carbide distribution, intra-lath and inter-lath, respectively, allows identifying both upper and lower bainite morphologies in the studied steels, as summarized in Table 2. In addition, overall transformation kinetics data reported elsewhere $^{10,11}$ of these bainitic steels are presented in Fig. 4a in terms of the start and finish reaction times. As expected, the bainite reaction is greatly retarded at lower transformation temperatures as carbon content is increased.

The carbon content of the bainitic ferrite, as analysed by APT in the three steels after completion of transformation as a function of temperature is shown in Fig. 4b. The results suggest that bainitic ferrite forms as a supersaturated solution of carbon, in spite of the fact that slow reaction rates had been determined at these temperatures. The explanation is that a sheaf of bainite consists of several sub-units and the experimental reaction rate applies to the whole bainite constituent, whereas it is proposed that each sub-unit grows with a velocity high enough to trap the carbon of the parent austenite. $^{12,13}$

What is also remarkable is that there is no essential difference in the observed results between steels that transform to upper or lower bainite. The examination of experimental data in Fig. 4b did not show any abrupt change of the carbon content in bainitic ferrite that could indicate a difference in bainite growth mechanism between high and low temperatures. This observation lends strong support for the opinion that the bainitic ferrite grows supersaturated with carbon independent of the transformation temperature and the overall reaction rate. As the transformation temperature is increased, carbon diffusion is enhanced, providing an opportunity for the decarburization of the supersaturated ferrite soon after the growth event. The excess carbon may then partition into the residual austenite or precipitate in the ferrite in the form of carbides. Therefore, the observed carbon content in solid solution in bainitic ferrite comes from the competition between the rate at which carbon is partitioned from super-saturated ferrite into austenite and the rate with which carbides can precipitate from ferrite.

\section{Effect of plastic accommodation defects on carbon partitioning into austenite}

The shape deformation associated with a displacive transformation of austenite in steel can be described as an invariant plane strain with a relatively large shear component. Christian $^{14}$ demonstrated that when the shape strain is elastically accommodated, the aspect ratio of the plate adjusts so that the strain energy is equal to the driving force. In ideal circumstances, where the transformation interface remains sliding throughout, and 
where there is no friction opposing the motion of the interface, thermoelastic equilibrium occurs. ${ }^{15}$

The thermoelastic equilibrium has been widely demonstrated for martensite, ${ }^{16}$ but it has not been straightforward for bainite. One reason for this is that the bainite transformation occurs at higher temperatures than those of martensite, where the austenite is mechanically weaker. The shape deformation therefore causes plastic deformation, and the resulting debris from dislocations eventually blocks the transformation interface ${ }^{17}$.

Carbon trapping at dislocations in the vicinity of the interface has been repetitively revealed in high carbon high silicon bainitic steels transformed at low temperature. ${ }^{18-20}$ The 6 at.- $\% \mathrm{C}$ isoconcentration surface shown in Fig. 5 outlines the carbon-enriched region around a dislocation and two austenite plates. It is evident from the proximity histogram across the dislocation-matrix interface in Fig. 5 that dislocations only trap the carbon atoms, as originally suggested by Kalish and Cohen. ${ }^{21}$

The average carbon levels of different Cottrell atmospheres detected by APT in the studied steels are listed in Table 2. The range (6-16 at. \%) for the amount of carbon trapped at dislocations is remarkable, and has no apparent correlation with the overall carbon content and the transformation temperature. Pereloma et al. ${ }^{22}$ found by APT that the extent of solute segregation to a dislocation depends on its position relative to other defects. In addition, Cochardt et al. ${ }^{23}$ pointed out that the atmosphere around a screw dislocation can bind more than twice the number of carbon atoms associated with an edge atmosphere. Therefore, some significant variation in the carbon level at different dislocations or different segments of dislocations would be expected.

It is believed that solute segregation on dislocations in the vicinity of the interface plays an important role in carbon redistribution during bainite transformation. Dislocations in austenite are inherited in the bainite after transformation and segregation at dislocations is expected to bind and, hence, prevent or hinder the carbon atoms from diffusing out of the ferrite lattice. This explains the small extent of carbon enrichment detected in the residual austenite as determined from XRD analysis and APT, during transformation at $200{ }^{\circ} \mathrm{C}$ in $\mathrm{Fe}-4.3 \mathrm{C}-2.8 \mathrm{Si}-1.8 \mathrm{Mn}-1.3 \mathrm{Cr}$ (at.-\%) steel (Fig. 1a). Moreover, the increase in the amount of carbon in bainitic ferrite as the transformation temperature decreased (Fig.4.b) is consistent with the fact that, the lower the reaction temperature, the higher the dislocation density of bainitic ferrite. ${ }^{24}$

\section{Cluster and carbides formation from supersaturated ferrite}

There are many observations that reveal that lower bainitic carbides nucleate and grow within supersaturated ferrite in a process identical to the tempering of martensite. ${ }^{25}$ The precipitation of intra-lath carbides during lower bainite reaction is a secondary process, not essential to the mechanism of formation of bainitic ferrite, except where any precipitation influences the reaction rate by removing carbon from the supersaturated ferrite. However, as discussed below, there are other complications, which can influence any changes in the sequence of precipitation during bainite formation.

The average carbon contents of different carbides formed during lower bainite reaction at different transformation temperatures in the studied steels were estimated from APT data with the use of proximity histograms across carbide/ferrite interfaces; the results are shown in Fig. 6. Examples of a carbon atom map showing carbon segregation across carbide particles are reported elsewhere. ${ }^{26}$ Based on the carbon content, the different types of carbides detected were as follows: 
i) Preferential agglomeration of carbon atoms in the bainitic ferrite matrix with a carbon content of 11-16 at. \% $\mathrm{C}$ and without evidence of substitutional solute partitioning.

ii) Particles with a carbon content of 17-26 at. \%, which might correspond to cementite or $\mathrm{Fe}_{4} \mathrm{C}$ carbon clusters with $\sim 20$ at. \% C. Cementite particles ideally contain a carbon content of 25 at. \%. However, an apparent low carbon concentration of cementite has also been reported in earlier atom probe studies. ${ }^{27}$ All the particles detected with this level of carbon have also shown clear evidence of substitutional solute partitioning across the interface. This additional information helps to discriminate between cementite and carbon clusters.

iii) Particles with a higher carbon content ranging from 27-30 at. \% $\mathrm{C}$ were identified as $\varepsilon$-carbides.

Matas and Hehemann ${ }^{28}$ first suggested that the initial carbide formed in lower bainite is $\varepsilon$-carbide, which is subsequently replaced by cementite. In the present work, both $\varepsilon$ carbide and cementite precipitated inside bainitic ferrite in the $1.3 \mathrm{C}-0.5 \mathrm{Si}$ (at.-\%) steel (Fig. 6). The rate at which the $\varepsilon$-carbide converts to cementite increases with temperature, but also depends on the steel composition. In fact, a high Si concentration retards the reaction, as is observed at all the temperature tested in the $1.3 \mathrm{C}-2.8 \mathrm{Si}$ (at $\%$ ), and 4.3C-2.8Si (at.-\%) steels in Fig. 6. Bhadeshia and Edmonds ${ }^{29}$ also failed to detect $\varepsilon$-carbide in high silicon, medium carbon steels, even during the early stages of the lower bainite transformation.

The detection of cementite instead of $\varepsilon$-carbide in lower bainite was rationalized in terms of carbon trapping at dislocations. ${ }^{30}$ The detection of cementite as the transformation temperature decreased in Fig. 6 is consistent with the fact that, the lower the reaction temperature, the higher the dislocation density in the bainitic ferrite. ${ }^{24}$ Carbon segregation at dislocations in the vicinity of the austenite/ferrite interface is other possible reaction that competes for carbon during carbide precipitation.

Carbon atom clusters, i.e., particles with a carbon content of 11-16 at. \% $\mathrm{C}$ and without evidence of substitutional solute partitioning, represented in Fig. 6 were also detected in the three steels at all the tested temperatures. The nature of the carbon atom clustering processes seems to be associated with a redistribution of solute to lattice defects ${ }^{31}$ and they might signify the onset of or precursors to carbide precipitation during the bainite reaction. $^{32}$

\section{Conclusion}

Bainite grows by displacive transformation; the growth is accompanied by a shape deformation which is an invariant-plane strain with a large shear component. The transformation is diffusionless but carbon atoms partition into the residual austenite (or precipitate as carbides), shortly after growth is arrested. The precipitation of carbides is therefore a secondary event.

\section{Acknowledgements}

Research was supported by ORNL's Shared Research Equipment (ShaRE) User Facility, which is sponsored by the Office of Basic Energy Sciences, Scientific User Facilities Division, U.S. Department of Energy. The authors also gratefully acknowledge the 
support of the Spanish Ministry of Science and Innovation for funding this research under the contract MAT2010-15330, respectively.

\section{References}

1. M. Hillert: 'Paradigm shift for bainite', Scripta Mater., 2002, 47, 175-180.

2. H.K.D.H. Bhadeshia and A.R. Waugh: 'Bainite: an atom-probe study of the incomplete-reaction phenomenon', Acta Metall. 1982, 30, 775-784.

3. I. Stark, G.D.W. Smith and H.K.D.H. Bhadeshia: 'The distribution of substitutional alloying elements during the bainite transformation', Metall. Trans. A, 1990, 21A, 837-844.

4. R.F. Hehemann, K.R. Kinsman and H.I. Aaronson: 'A debate on the bainite reaction', Met. Trans. 1972, 3, 1077-1093.

5. H.K.D.H. Bhadeshia: 'A rationalisation of shear transformations in steels', Acta Metall. 1981, 29, 1117-1130.

6. F.G. Caballero and H.K.D.H. Bhadeshia: 'Very strong bainite', Curr. Opin. Solid State Mater. Sci., 2004, 8, 251-257.

7. P, Self, H.K.D.H. Bhadeshia and W.M. Stobbs: 'Lattice spacing from lattice fringes', Ultramicroscopy, 1981, 6, 29-40.

8. F.G. Caballero, C. Garcia-Mateo, M.J. Santofimia, M.K. Miller and C. Garcia de Andres: 'New experimental evidence on the incomplete transformation phenomenon in steel', Acta Mater. 2009, 57, 8-17.

9. F.G. Caballero, M.K. Miller, C. Garcia-Mateo, J. Cornide and M.J. Santofimia: 'Temperature dependence of carbon supersaturation of ferrite in bainitic steels', Scripta Mater. 2012, 67, 846-849.

10. M.J. Santofimia, F.G. Caballero, C. Capdevila, C. Garcia-Mateo, C. Garcia de Andres: 'Evaluation of displacive models for bainite transformation kinetics in steels', Mater. T. JIM, 2006,47, 1492-1500.

11. C. Garcia-Mateo, F.G. Caballero and H.K.D.H. Bhadeshia: 'Acceleration of lowtemperature bainite', ISIJ Int. 2003, 43, 1821-1825.

12. H.K.D.H. Bhadeshia: 'Kinetics, solute-drag and mechanism of the bainite reaction in steels', in 'Proceedings of an International Conference on Phase Transformations in Ferrous Alloys', (eds. A.R. Marder and J.I. Goldstein), 335-340; 1984, Philadelphia, AIME.

13. A. Ali and H.K.D.H. Bhadeshia: 'Growth rate data on bainite in alloy steels', Mater. Sci. Technol., 1989, 5, 398-402.

14. J.W. Christian: 'Accommodation strains in martensite formation, and the use of a dilatation parameter', Acta Metall., 1958, 6, 377-379.

15. G.V. Kurdyumov and L.G. Khandros: 'On the thermoelastic equilibrium on martensitic transformations', Dokl. Akad. Nauk SSSR, 1949, 66, 211-214.

16. M.X. Zhang and P.M. Kelly: 'Crystallographic features of phase transformations in solids', Prog. Mater Sci., 2009, 54, 1101-1170.

17. M. Nemoto: 'High voltage electron microscopy', 1974, New York, Academic Press.

18. F.G. Caballero, M.K. Miller, S.S. Babu and C. Garcia-Mateo: 'Atomic scale observations of bainite transformation in a high carbon high silicon steel', Acta Mater,. 2007, 55, 381-390.

19. J. Cornide, G. Miyamoto, F.G. Caballero, T. Furuhara, M.K. Miller and C. GarciaMateo: 'Distribution of dislocations in nanostructured bainite', Solid State Phenomena, 2011, 172-174, 117-122.

20. F.G. Caballero, H-W. Yen, M.K. Miller, J-R. Yang, J. Cornide, C. Garcia-Mateo: 'Complementary use of transmission electron microscopy and atom probe 
tomography for the examination of plastic accommodation in nanocrystalline bainitic steels', Acta Mater. 2011, 59, 6117-6123.

21. D. Kalish and M. Cohen: 'Structural changes and strengthening in the strain tempering of martensite', Mater. Sci. Eng., 1970, 6, 156-166.

22. E.V. Pereloma, I.B. Timokhina, J.J. Jonas and M.K. Miller: 'Fine-scale microstructural investigations of warm rolled low-carbon steels with and without $\mathrm{Cr}$, P, and B additions', Acta Mater., 2006, 54, 4539-4551.

23. A. Cochardt, G. Schoeck and H. Wiedersich: 'Interaction between dislocations and interstitial atoms in body-centered cubic metals', Acta Metall., 1955, 3, 533-537.

24. M.K. Fondekar, A.M. Rao, and A.K. Mallik: 'Strain tempering of bainite', Metall. Trans., 1970, 1, 885-890.

25. H.K.D.H. Bhadeshia: 'The lower bainite transformation and the significance of carbide precipitation', Acta Mater., 1980, 28, 1103-1114.

26. F.G. Caballero, M.K. Miller and C. Garcia-Mateo: 'Atom probe tomography analysis of precipitation during tempering of a nanostructured bainitic steel', Metall. Mater. Trans. A, 2011, 42, 3660-3668.

27. M.K. Miller, P.A. Beaven, S.S. Brenner and G.D.W. Smith: 'An atom probe study of the aging of iron-nickel-carbon martensite', Metall. Trans. A, 1983,14, 10211024.

28. S.J. Matas and R.F. Hehemann: 'The structure of bainite in hypoeutectoid steels', Trans AIME, 1968, 221, 179-185.

29. H.K.D.H. Bhadeshia and D.V. Edmonds, 'The bainite transformation in a silicon steel', Metall. Trans., 1979, 10A, 895-907.

30. H.K.D.H. Bhadeshia: 'Theoretical analysis of changes in cementite composition during the tempering of bainite', Mater. Sci. Technol., 1989, 5, 131-137.

31. M.K. Miller, P.A. Beaven, G.D.W. Smith: 'A study of the early stages of tempering of iron-carbon martensites by atom probe field ion microscopy', Metall. Trans. A, 1981, 12, 1197-1204.

32. K.A. Taylor, G.B. Olson, M. Cohen and J.B. Van der Sande: 'Carbide precipitation during stage I tempering of Fe-Ni-C martensites’, Metall. Trans. A, 1989, 20, 27492765 . 


\section{Table Captions:}

Table 1: Carbide distribution and morphology observed after bainite transformation in steels with different carbon and silicon contents.

Table 2: Carbon trapped at dislocations determined by APT after bainite transformation in steels with different carbon and silicon contents.

\section{Figure Captions:}

Figure 1. Carbon content in (a) austenite and (b) bainitic ferrite determined by XRD analysis and APT in a $\mathrm{Fe}-4.3 \mathrm{C}-2.8 \mathrm{Si}-1.8 \mathrm{Mn}-1.3 \mathrm{Cr}$ (at.-\%) steel as bainite transformation progress at $200{ }^{\circ} \mathrm{C}$.

Figure 2. Carbon atom map showing a ferrite/austenite interface. $\alpha$ is bainitic ferrite and $\gamma$ is austenite.

Figure 3. Carbon content in austenite measured by APT as a function of the thickness in $\mathrm{nm}$ of the analyzed austenite regions in a $\mathrm{Fe}-4.3 \mathrm{C}-2.8 \mathrm{Si}-1.8 \mathrm{Mn}-1.3 \mathrm{Cr}$ (at.-\%) steel isothermally transformed at $200^{\circ} \mathrm{C}$.

Figure 4. (a) Start and finish bainite reaction times as a function of transformation temperature; (b) carbon content in bainitic ferrite determined by APT after bainite reaction at different temperatures in steels with the approximated composition of $\mathrm{Fe}-\mathrm{XC}-\mathrm{YSi}-1.5 \mathrm{Mn}-0.5 \mathrm{Cr}$ (at.-\%).

Figure 5. Carbon isoconcentration surfaces at 6 at.- $\% \mathrm{C}$, and proximity histograms across a dislocation in ferrite in the vicinity of two austenite plates. $\gamma$ is austenite.

Figure 6. Average carbon content estimated from APT data of different particles formed during lower bainite reaction at different temperatures in steels with the approximated composition of $\mathrm{Fe}$ XC-YSi-1.5Mn-0.5Cr (at.-\%). 
Table 1: Carbide distribution and morphology observed after bainite transformation in steels with different carbon and silicon contents.

\begin{tabular}{lllll}
\hline $\begin{array}{l}\text { Fe-XC-YSi-1.5Mn-0.5Cr* } \\
\text { at.-\% }\end{array}$ & $\begin{array}{l}\text { Temperature } \\
{ }^{\circ} \mathrm{C}\end{array}$ & $\begin{array}{l}\text { Time } \\
\mathrm{s}\end{array}$ & Carbide distribution & Bainite Morphology \\
\hline $1.3 \mathrm{C}-0.5 \mathrm{Si}$ & 525 & 1,800 & Inter-lath & Upper bainite \\
& 500 & 1,800 & Inter-lath & Upper bainite \\
& 475 & 1,800 & Inter-lath & Upper bainite \\
& $\mathrm{LB}_{\mathrm{S}}=450^{\circ} \mathrm{C}$ & & & Mixed ${ }^{\dagger}$ \\
& 425 & 1,800 & Inter and Intra-lath & Lower bainite \\
& 400 & 1,800 & Inter and Intra-lath & Lower bainite \\
& 375 & 1,800 & Inter and Intra-lath & Lower bainite \\
\hline $1.3 \mathrm{C}-2.8 \mathrm{Si}$ & 425 & 1,000 & Carbide-free & Upper bainite \\
& $\mathrm{LB}_{\mathrm{S}}=400^{\circ} \mathrm{C}$ & & & Mixed* \\
& 375 & 1,100 & Intra-lath & Lower bainite \\
& 350 & 1,350 & Intra-lath & Lower bainite \\
& 325 & 1,350 & Intra-lath & Lower bainite \\
\hline $4.3 \mathrm{C}-2.8 \mathrm{Si}$ & 300 & 43,200 & Intra-lath & Lower bainite \\
& 250 & 108,000 & Intra-lath & Lower bainite \\
& 200 & 864,000 & Intra-lath & Lower bainite \\
\hline
\end{tabular}

* Approximated steel composition.

$\uparrow$ The observation of inter- and intra-lath carbide distributions allowed defining the lower bainite start (LB $)$ temperature. UB is upper bainite and LB is lower bainite 
Table 2: Carbon trapped at dislocations determined by APT after bainite transformation in steels with different carbon and silicon contents.

\begin{tabular}{lll}
\hline $\begin{array}{l}\text { Fe-XC-YSi-1.5Mn-0.5Cr* } \\
\text { at.-\% }\end{array}$ & $\begin{array}{l}\text { Temperature } \\
{ }^{\circ} \mathrm{C}\end{array}$ & $\begin{array}{l}\text { Carbon in Cottrell atmosphere } \\
\text { at. } \%\end{array}$ \\
\hline $1.3 \mathrm{C}-0.5 \mathrm{Si}$ & 525 & $11.0 \pm 1.6 \dagger$ \\
& & $10.0 \pm 1.6$ \\
& & $14.3 \pm 2.4$ \\
\hline $1.3 \mathrm{C}-2.8 \mathrm{Si}$ & 350 & $12.2 \pm 0.4$ \\
& & $9.6 \pm 2.9$ \\
& $14.4 \pm 2.9$ \\
& $13.0 \pm 1.7$ \\
& & $16.3 \pm 2.9$ \\
\hline $4.3 \mathrm{C}-2.8 \mathrm{Si}$ & $14.0 \pm 2.2$ \\
& 200 & $7.4 \pm 0.1$ \\
& & $7.4 \pm 2.6$ \\
& & $5.8 \pm 3.0$ \\
& & $13.4 \pm 0.8$ \\
\hline
\end{tabular}

* Approximated steel composition.

$\uparrow$ Error bars representing the statistical scatter in the APT composition profiles due to the number of ions in each slice of the selected volume of analysis. 

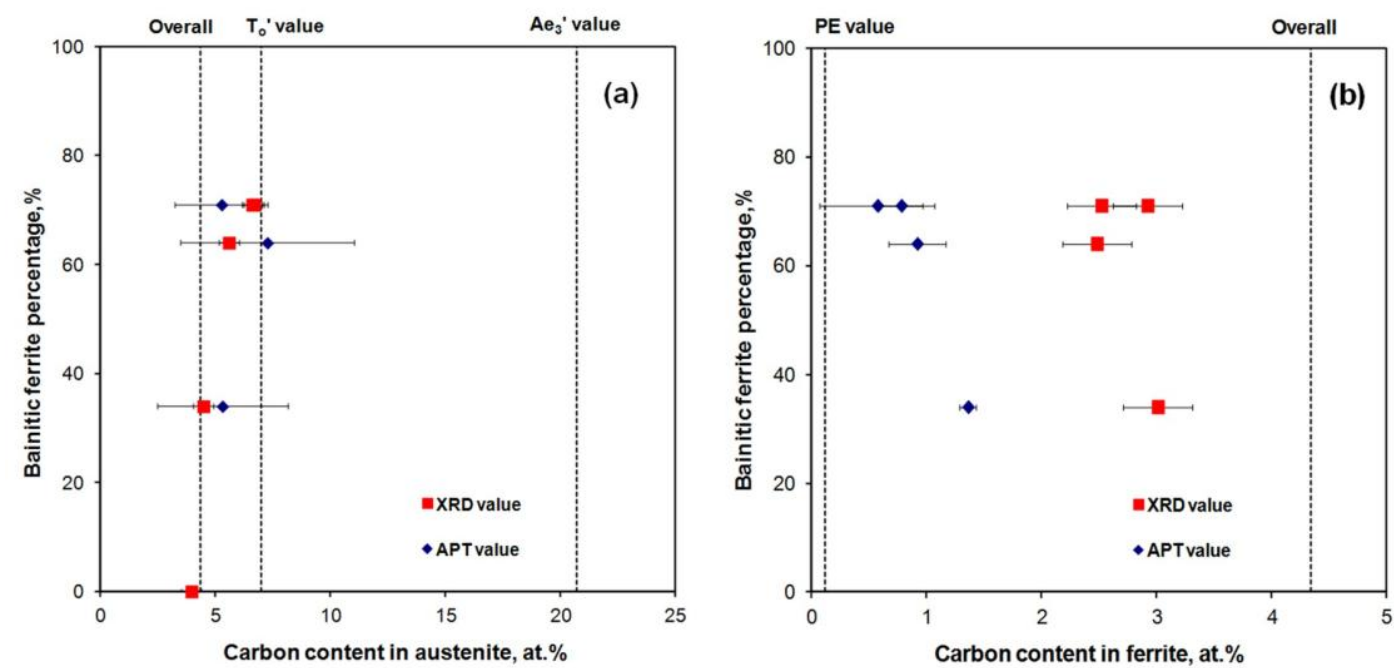

Figure 1. Carbon content in (a) austenite and (b) bainitic ferrite determined by XRD analysis and APT in a $\mathrm{Fe}-4.3 \mathrm{C}-2.8 \mathrm{Si}-1.8 \mathrm{Mn}-1.3 \mathrm{Cr}$ (at.-\%) steel as bainite transformation progress at $200{ }^{\circ} \mathrm{C}$. 


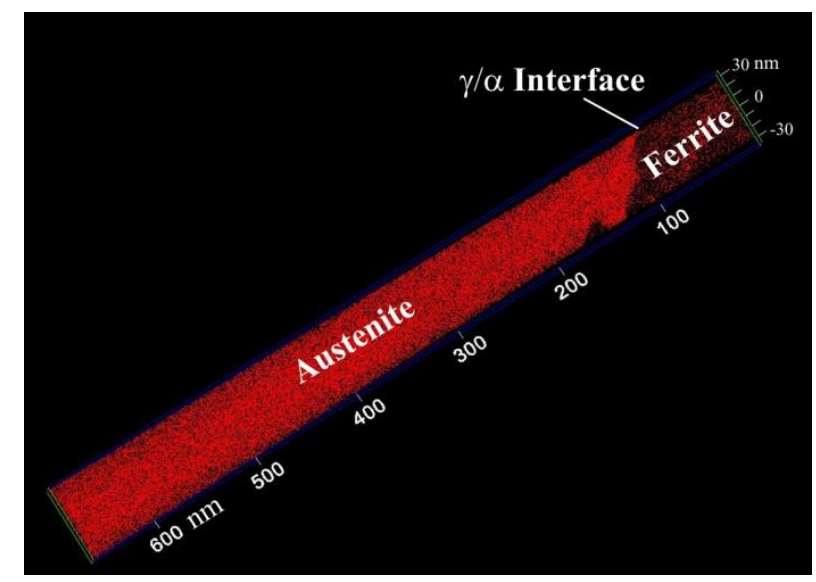

Figure 2. Carbon atom map showing a ferrite/austenite interface. $\alpha$ is bainitic ferrite and $\gamma$ is austenite. 


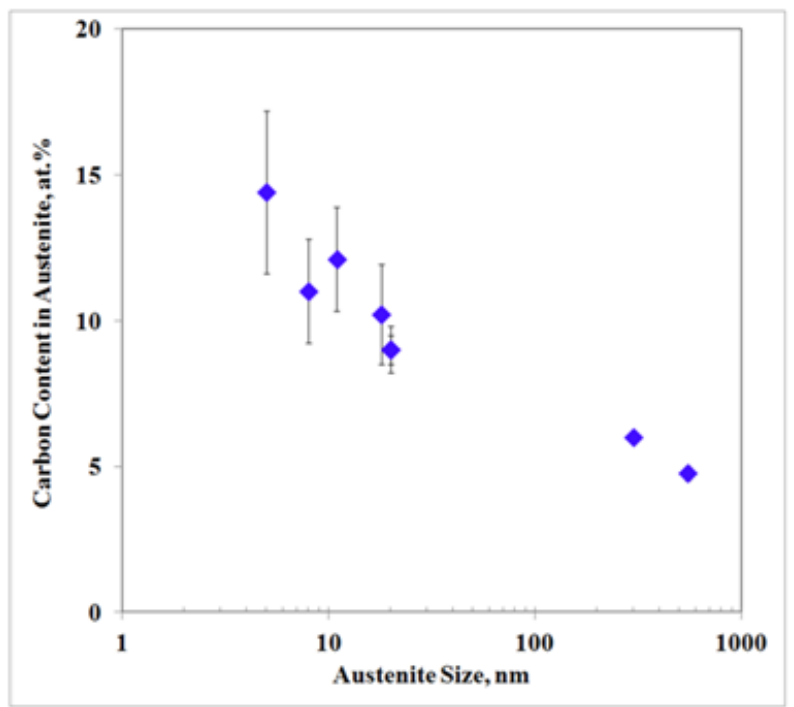

Figure 3. Carbon content in austenite measured by APT as a function of the thickness in $\mathrm{nm}$ of the analyzed austenite regions in a $\mathrm{Fe}-4.3 \mathrm{C}-2.8 \mathrm{Si}-1.8 \mathrm{Mn}-1.3 \mathrm{Cr} \quad($ at.- $\%)$ steel isothermally transformed at $200^{\circ} \mathrm{C}$. 

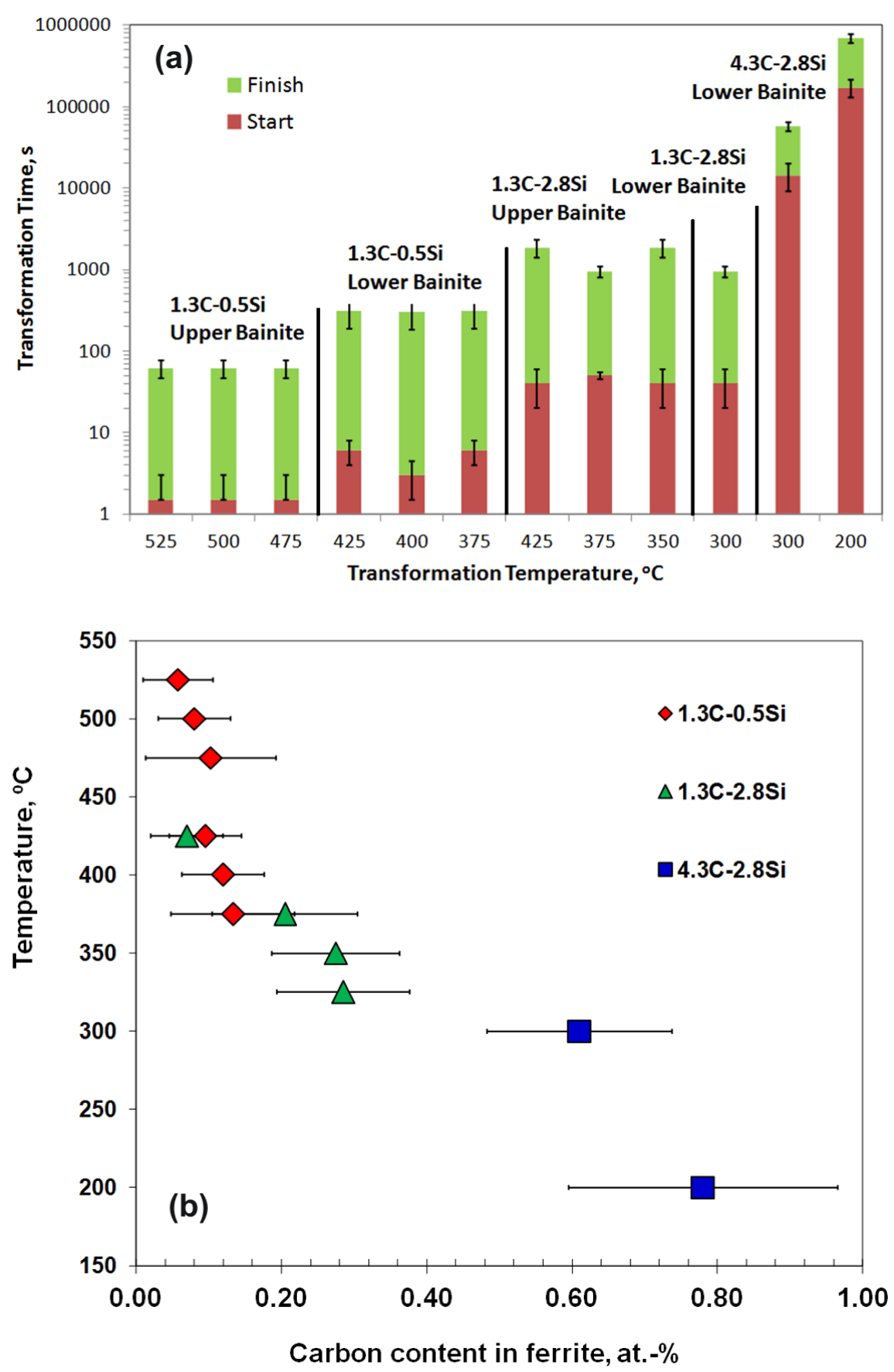

Figure 4. (a) Start and finish bainite reaction times as a function of transformation temperature; (b) carbon content in bainitic ferrite determined by APT after bainite reaction at different temperatures in steels with the approximated composition of $\mathrm{Fe}-\mathrm{XC}-\mathrm{YSi}$ $1.5 \mathrm{Mn}-0.5 \mathrm{Cr}($ at. $-\%)$. 


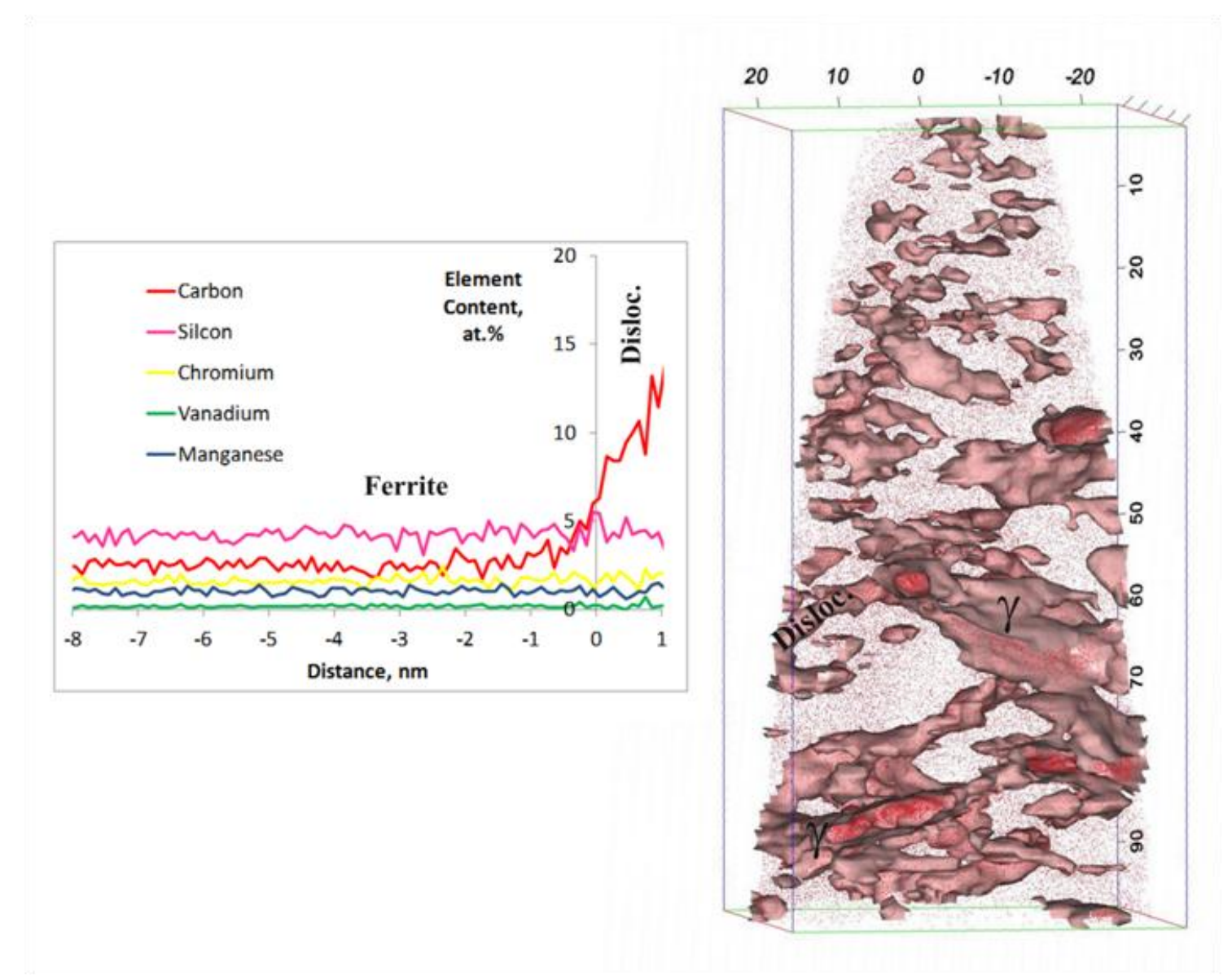

Figure 5. Carbon isoconcentration surfaces at 6 at.- $\% \mathrm{C}$, and proximity histograms across a dislocation in ferrite in the vicinity of two austenite plates. $\gamma$ is austenite. 


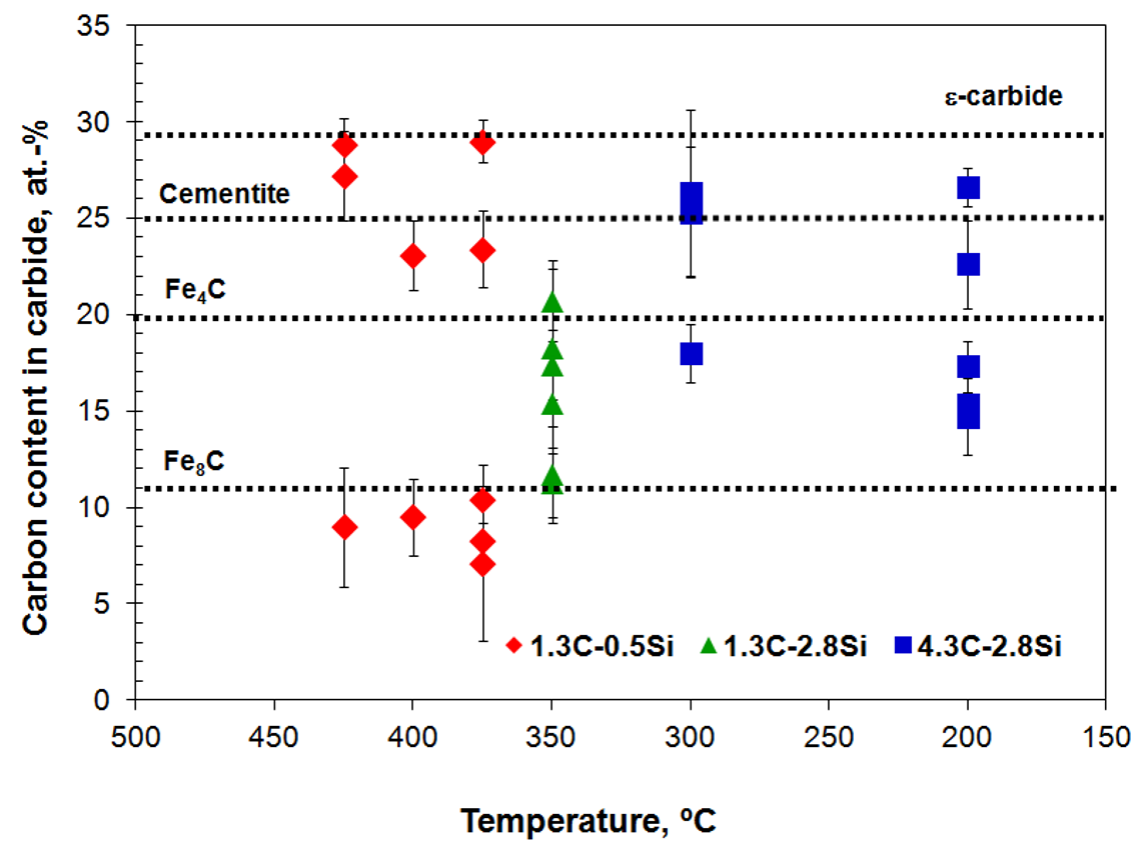

Figure 6. Average carbon content estimated from APT data of different particles formed during lower bainite reaction at different temperatures in steels with the approximated composition of Fe-XC-YSi-1.5Mn-0.5Cr (at.-\%). 